\title{
Individual evaluation of DEP, EP and AC-EOF effects on $\lambda$ DNA molecules in a DNA concentrator
}

\section{$\operatorname{AUTHOR}(\mathrm{S}):$}

Yokokawa, Ryuji; Manta, Yoshihiro; Namura, Moriaki; Takizawa, Yusuke; Le, Nam Cao Hoai; Sugiyama, Susumu

\section{CITATION:}

Yokokawa, Ryuji ... [et al]. Individual evaluation of DEP, EP and AC-EOF effects on $\lambda$ DNA molecules in a DNA concentrator. Sensors and Actuators B: Chemical 2010, 143(2): 769-775

\section{ISSUE DATE:}

2010-01-07

URL:

http://hdl.handle.net/2433/95085

\section{RIGHT:}

(C) 2009 Elsevier B.V. All rights reserved.; This is not the published version. Please cite only the published version.; この論文は出版社版で ありません。引用の際には出版社版をご確認ご利用ください。 
Elsevier Editorial System(tm) for Sensors \& Actuators: B. Chemical Manuscript Draft

Manuscript Number: SNB-D-09-00800R1

Title: Individual evaluation of DEP, EP and AC-EOF effects on ? DNA molecules in a DNA concentrator

Article Type: Research Paper

Keywords: DNA concentrator, Micro Total Analysis Systems (MicroTAS), dielectrophoresis (DEP), electrophoresis (EP), AC electroosmotic flow (AC-EOF)

Corresponding Author: Prof. Ryuji Yokokawa, Ph.D.

Corresponding Author's Institution: Kyoto Univ.

First Author: Ryuji Yokokawa, Ph.D.

Order of Authors: Ryuji Yokokawa, Ph.D.; Yoshihiro Manta; Moriaki Namura; Yusuke Takizawa; Nam Cao Hoai Le; Susumu Sugiyama

Abstract: Bio concentrators have been proposed to concentrate and detect tiny amount of cells, DNAs, or proteins in a microfluidic system. Concentrating processes have been experimentally studied and discussed as a result of concentration caused by multiple electrokinetic phenomena. Here, we have investigated individual electrokinetic phenomenon in a DNA concentrator to propose a design guide for a micro bio concentrator. Three dominant electrokinetic phenomena: dielectrophoresis (DEP), electrophoresis (EP), and AC electroosmotic flow (AC-EOF) are experimentally and theoretically evaluated. DNA mobility due to DEP was separately studied by utilizing quadrupole electrodes generating a uniform field gradient, which enables us to derive a DEP force on the order of 10-13 N acting on a single DNA molecule. Using the theoretical model the DEP force on the order of 10-12 N, close to the experimental result, was calculated. The EP force estimated from the average charge per base pair of DNA molecule was on the order of 10-9 N. Compared with these two forces, AC-EOF generating a flow velocity of 100 200 $\mathrm{m} / \mathrm{s}$, globally dominates the manipulation of DNA molecules throughout the concentrator. However, the three-dimensional observation of molecule distribution reveals that the EP force has a significant role in holding the DNA molecules at the electrode centre. The results not only support the proposal that the biomolecular concentrator should be designed to utilize AC-EOF and EP [1,2], but also provide approximate estimates for the DEP and EP forces, and the AC-EOF velocity which will allow us to design a concentrator with a given experimental condition. 


\title{
Individual evaluation of DEP, EP and AC-EOF effects on $\lambda$ DNA molecules in a DNA concentrator
}

\author{
Ryuji YoKoKawa, ${ }^{1,2,3}$ YOShihiro Manta, ${ }^{4}$ Moriaki NAmura, ${ }^{3}$ Yusuke Takizawa, ${ }^{3}$ Nam CaO Hoai \\ LE $^{4}$ AND SUSUMU SUGIYAMA ${ }^{5}$
}

${ }_{5}^{1}$ Department of Microengineering, Kyoto University, Yoshida-honmachi, Sakyo-ku, Kyoto 606-8501, Japan. Fax: 8175753 3559; Tel: 8175753 3559; *E-mail:ryuji@me.kyoto-u.ac.jp

${ }^{2}$ PRESTO/CREST JST, 4-1-8, Hon-chou, Kawaguchi, Saitama 332-0012, Japan

${ }^{3}$ Department of Micro System Technology, Ritsumeikan University, 1-1-1 Noji-Higashi, Kusatsu, Shiga 525-8577, Japan.

${ }_{10}^{4}$ Graduate School of Science and Engineering, Ritsumeikan University, 1-1-1 Noji-Higashi, Kusatsu, Shiga 525-8577, Japan

${ }^{5}$ Ritsumeikan Global Innovation Research Organization, Ritsumeikan University, 1-1-1 Noji-Higashi, Kusatsu, Shiga 525-8577, Japan

${ }_{15}$ Keywords: DNA concentrator, Micro Total Analysis Systems (MicroTAS), dielectrophoresis (DEP), electrophoresis (EP), AC electroosmotic flow (AC-EOF)

Bio concentrators have been proposed to concentrate and detect tiny amount of cells, DNAs, or proteins in a microfluidic system. Concentrating processes have been experimentally studied and discussed as a result of concentration caused by ${ }_{20}$ multiple electrokinetic phenomena. Here, we have investigated individual electrokinetic phenomenon in a DNA concentrator to propose a design guide for a micro bio concentrator. Three dominant electrokinetic phenomena: dielectrophoresis (DEP), electrophoresis (EP), and AC electroosmotic flow (AC-EOF) are experimentally and theoretically evaluated. DNA mobility due to DEP was separately studied by utilizing quadrupole electrodes generating a uniform field gradient, which enables us to derive a DEP force on the order of $10^{-13} \mathrm{~N}$ acting on a single DNA molecule. Using the ${ }_{25}$ theoretical model the DEP force on the order of $10^{-12} \mathrm{~N}$, close to the experimental result, was calculated. The EP force estimated from the average charge per base pair of DNA molecule was on the order of $10^{-9} \mathrm{~N}$. Compared with these two forces, AC-EOF generating a flow velocity of 100 200 $\mu \mathrm{m} / \mathrm{s}$, globally dominates the manipulation of DNA molecules throughout the concentrator. However, the three-dimensional observation of molecule distribution reveals that the EP force has a significant role in holding the DNA molecules at the electrode centre. The results not only support the proposal that 30 the biomolecular concentrator should be designed to utilize AC-EOF and EP [1, 2], but also provide approximate estimates for the DEP and EP forces, and the AC-EOF velocity which will allow us to design a concentrator with a given experimental condition. 


\section{Introduction}

A detector for biomolecules is a key component to achieve practical micro total analysis systems ( $\mu$ TAS). Biomolecules of nanometre scale cannot be easily manipulated by the same scheme demonstrated at micrometre scales using dielectrophoretic force only. To achieve highly sensitive biomolecule detection by manipulating target molecules, combination of electrokinetic phenomena have been proposed by many researchers [1-4]. Dominant phenomena are dielectrophoresis (DEP), electrophoresis (EP), and AC electroosmotic flow (AC-EOF) $[5,6]$.

Dielectrophoretic force acting on a particle with an induced dipole moment is generated by the inhomogeneous field [7]. The magnitude and direction of dielectrophoretic force are defined by electrical properties of the particle and its surrounding medium. When the particle is more polarizable than the medium, the force drives the particle to higher electric field area (Positive DEP). On the contrary, when the relative polarizability is reversed, the direction of moving particle is opposite, i.e. to the lower electric field (Negative DEP). The time-averaged DEP force for a spherical particle is defined by

$$
F_{D E P}=2 \pi r_{e}^{3} \varepsilon_{m} \operatorname{Re}[K(\omega)] \nabla\left|E_{r m s}\right|^{2},
$$

where $r_{e}$ is the particle radius, $\varepsilon_{m}$ the permittivity of the medium, $\operatorname{Re}[K(\omega)]$ the real part of the Clausius-Mossoti factor, and $E_{r m s}$ the root mean square electric field.

Dielectrophoretic manipulations of micrometre and submicrometre particles have been initiated by Washizu and coworkers [8, 9], and demonstrated for numerous applications in recent years $[10,11]$. Most of their work involves cell handling and sorting. For example, parallel cell manipulation was achieved by an array of electrodes [12], quadrupole electrodes [13], and spiral electrodes [14]. As cell sorting applications, cells are separated into living or dead [15], cancerous or healthy [16], and labeled with antibody or not [17, 18]. More recently, dielectric parameters for particles were characterized and controlled for manipulations [19, 
20]. Particle size in such applications are in tens of micrometres in diameter, which provides dielectrophoretic force in $\mathrm{pN}$ range. Such force is large enough to move each cell.

However, DEP force is proportional to the third power of a particle radius according to eq. (1). The force decreases very rapidly with diameter, and can go below the threshold value that cannot overcome Brownian motion. Therefore, it is necessary to introduce other strategy to manipulate biomolecules in the nanometre range such as DNA molecules. A recent solution is to utilize AC-EOF for driving the fluid including molecules and then to take advantage of DEP/EP forces for handling them where the electric field is strong enough [1, 2, 21, 22].

$\mathrm{AC}-\mathrm{EOF}$ is a fluid flow phenomenon induced by $\mathrm{AC}$ voltage between coplanar electrodes, where the frequencies must be below the charge relaxation frequency of the fluid. The surface charges on the electrodes attract counterions and repel coions in the fluid to keep local charge balance, yielding an electrical double layer (EDL). When an alternating potential is applied to the electrodes, a nonuniform electric field is generated. The tangential component of the field produces a force on the EDL, which is always in the direction toward the electrode center. This is because the charge induced on the electrode is opposite, though the tangential component of the field is in the same direction on the two electrodes. This mobility of EDL produces a unidirectional vortical flow. Theoretical and experimental approaches were summarized by many researchers [23-25]. Applications using AC-EOF were reported for pumping [26, 27], mixing of chemicals [28], and cell positioning [29].

EP is an effective technique to handle charged particles. Since most biomolecules are negatively charged, an electric field yields an EP force directed to the higher potential region. For a molecule with charge $q$ in a steady electric field $E$, the electrophoretic force is simply determined by

$$
F_{E P}=q E
$$

Once the effective charge $q$ is determined, one can easily estimate the force acting on a molecule. However, the EDL and other parameters of biomolecule and media complicate 
direct derivation of the EP force, so the EP mobility, $\mu_{E P}=v_{E P} / E$, of charged biomolecules has been traditionally measured and the effective charge density then derived [30-32]. This is because biomolecule separation by fractionating molecules according to molecular size is an essential technique to purify target molecules. Even when the charge density was measured using a nanopore, charge density fell in the similar range [33]. Therefore, EP force acting on a DNA molecule can be estimated based on reported parameters. Details will follow in the discussion section.

Due to the limited DEP effect on nanometre particles, $\mu$ TAS researchers have recently developed biomolecular concentrators by AC-EOF and EP [1, 2]. Especially DNA molecules and $E$. coli cells are well concentrated on a circular electrode by applying an AC potential with DC offset. From experimental results on a DNA concentrator, Wong and Bown recently concluded that the DNA molecules flowed to the center electrode by AC-EOF, and remained on the electrode surface by EP force.

Such DNA concentrators have been developed based on experimental trial and error to achieve the effective increase of fluorescent intensity. Bown and coworkers computed, by experimental results but also by theoretical and numerical approaches, DNA mobility on the center electrode. This represents a significant advance to help understand the concentration phenomena, because it is important for $\mu \mathrm{TAS}$ researchers to specify experimental parameters from known material properties. For example, the concentrator dimensions, AC voltage, frequency, media conductivity required must be specified to match the selected target molecule. To contribute to such issues of design protocol, we separately measured DEP force and AC-EOF velocity, and also calculated DEP and EP forces and AC-EOF velocity based on simple theories. Such simple calculations make it possible to predict the mobility of given biomolecules in a concentrator. 


\section{Material and methods}

\section{Device fabrication}

Electrodes were fabricated on a glass coverslip $(18 \times 60 \mathrm{~mm}$, No. $1: 0.12-0.17 \mathrm{~mm}$ in thickness, Matsunami) by conventional photolithography processes. Indium Tin Oxide (ITO) was spputtered to $50 \mathrm{~nm}$ thickness, and photoresist (S1818, Shipley) was spincoated (500 rpm $-5 \mathrm{~s}, 3000 \mathrm{rpm}-30 \mathrm{~s})$. After photolithography, the ITO layer was etched by an etchant ( $\mathrm{HCl}$ : $\mathrm{HNO}_{3}: \mathrm{H}_{2} \mathrm{O}=5: 20: 75$ ) for $70 \mathrm{~s}$ using the photoresist as an etching mask. Following resist removal by acetone, the coverslip was thoroughly washed by ethanol and deionized water (DIW).

For DEP experiments, quadrupole electrodes were patterned to have a $10 \mu \mathrm{m}$ gap between opposing electrodes as shown in Fig. 1a. This electrode gap is 13-fold smaller than that reported by Watarai and coworkers [34] to yield enough DEP force on DNA molecules. For a DNA concentrator to measure AC-EOF velocity and to achieve DNA concentration, electrodes consisted of a centre electrode and an outer electrode, following Wong [1] and Bown [2] (Fig. 1b). However, our experiments require smaller electrodes to visualize each DNA molecule and to cover the whole electrode in the field of view under a 100x objective lens. We have downsized the diameter of the centre electrode, the gap between the electrodes, and width of the outer electrode to $55 \mu \mathrm{m}, 10 \mu \mathrm{m}$, and $10 \mu \mathrm{m}$, respectively.

\section{Sample preparation}

A blocking reagent was prepared by dissolving bovine serum albumin (BSA, A7906, Sigma) powder in DIW. A DNA solution was prepared by mixing $\lambda$ DNA (3010, Takara Bio Inc., Japan) and YOYO-1 (Y3610, Invitrogen Corp., USA). Their final concentrations were 3.8 $\mathrm{pg} / \mu \mathrm{L}$ for $\lambda \mathrm{DNA}$ and $0.6 \mathrm{nM}$ for YOYO-1 in DEP and AC-EOF measurements, and 0.38 $\mathrm{ng} / \mu \mathrm{L}$ and $60 \mathrm{nM}$ in the visualization of three dimensional DNA molecule distributions. In all 
experiments, the buffer solution used was phosphate buffered saline (PBS) with $0.1 \%$ Tween 20, which was diluted to a conductivity of $2 \mathrm{mS} / \mathrm{m}$.

\section{Experimental setup}

All coverslips with electrodes were coated with $1 \mathrm{mg} / \mathrm{mL}$ BSA solution before starting experiments to prevent nonspecific adhesion of DNA molecules. DNA solutions were confined above the electrodes by using a PDMS spacer and coverslip, providing a cylindrical chamber $2 \mathrm{~mm}$ in diameter and $50 \mu \mathrm{m}$ in height. The device was placed on the stage of an inverted microscope equipped with an oil immersion objective lens (IX71, UPLFLN 100× oil objective, Olympus Corp., Japan). Compared with other DNA concentrators, the transparent ITO electrodes enable us to focus on DNA molecules close to the electrode surface. In this experimental setup we could distinguish each $\lambda$ DNA molecule for particle tracking velocimetry (PTV).

An AC potential was applied by a function generator (WF1943B, NF Corp., Japan) and monitored by an oscilloscope (DPO4104, Tektronix Inc., Japan). The voltage applied was always set to $5 \mathrm{~V}_{\mathrm{pp}}$ between $10-\mu \mathrm{m}$ gap in both quadrupole electrodes and DNA concentrators, resulting in a maximum field intensity of $2.5 \mathrm{kV} / \mathrm{cm}$. Mobility of DNA molecules was captured by an EM-CCD camera (iXon EM+ DU-897, Andor Technology PLC, Ireland). Sequential images were analyzed with two PC-based softwares: Move-tr/2D (Library Co., Ltd., Japan) for tracking DNA molecules and Andor iQ (Andor Technology PLC, Ireland) for fluorescent intensity analysis. In the fluorescent intensity measurement, data were obtained as the average fluorescent intensity in a circular area $\left(39\right.$ pixel $\left.=6.1 \mu \mathrm{m}^{2}\right)$, where the highest average fluorescent intensity was measured. In addition to such conventional fluorescent imaging techniques, three dimensional distributions of DNA molecules on the center electrode was also obtained by a confocal laser scanning system (CSU-X1, Yokogawa Electric Corp., Japan). 


\section{Results and discussion}

\section{DEP in quadrupole electrodes}

As proposed by Huang and Pethig [35], spatial variation of the field $|E|$ and DEP force factor $\nabla\left|E_{r m s}\right|^{2}$ are derived for various electrodes. For the quadrupole electrode case, the DEP force factor is defined as

$$
\nabla\left|E_{r m s}\right|^{2}=\frac{2 R U_{r m s}^{2}}{d^{4}}
$$

where $R$ is the radial distance from the electrode centre, $U_{r m s}$ applied voltage (root mean square), and $d$ the distance from the electrode centre $(d=0 \sim 5 \mu \mathrm{m}$ in our quadrupole electrodes shown in Fig. 1a) [34]. Polystyrene particles [36, 37], virus [38], and DNA [39] have been handled for fundamental DEP study in the quadrupole electrodes. Assuming that the DEP force and the Stokes drag force,

$$
F_{s t}=6 \pi \eta r_{e} v
$$

are balanced in the quadrupole electrodes, the mobility coefficient, $\alpha$, is derived as [36]

$$
\alpha=\frac{2 r_{e}^{2} \varepsilon_{m} U_{r m s}^{2} \operatorname{Re}[K(\omega)]}{3 \eta d^{4}} .
$$

Here $\eta$ and $v$ are the fluid viscosity and the particle velocity, respectively. Therefore, the velocity is found to be proportional to the particle position with proportionality constant $\alpha$, i.e. $v=\alpha R$. The DNA velocity from experimental results are plotted against the particle position in Fig. 2 depending on applied frequencies. From these values of $\alpha$, the time-averaged DEP force can be obtained

$$
F_{D E P}=6 \pi \eta r_{e} \alpha R
$$

which is derived by eqs. (1), (4) and (5). Experimentally obtained $F_{D E P}$ for $R=2,3,4 \mu \mathrm{m}$ are plotted in Fig. 3. The force has the range of $5.8 \times 10^{-14} \sim 1.2 \times 10^{-13} \mathrm{~N}$ and $-1.4 \times 10^{-13} \sim 4.4 \times 10^{-14}$ $\mathrm{N}$ for positive and negative DEP, respectively. 
At the same time, we numerically estimated $F_{D E P}$ from eqs. (1), (3), with $\operatorname{Re}[K(\omega)]$ defined by:

$$
\begin{aligned}
& \operatorname{Re}[K(\omega)]=\frac{\varepsilon_{p}-\varepsilon_{m}}{\varepsilon_{p}+2 \varepsilon_{m}}+\frac{3\left(\varepsilon_{m} \sigma_{p}-\varepsilon_{p} \sigma_{m}\right)}{\tau\left(\sigma_{p}+2 \sigma_{m}\right)^{2}\left(1+\omega^{2} \tau^{2}\right)} \\
& \tau=\frac{\varepsilon_{p}+2 \varepsilon_{m}}{\sigma_{p}+2 \sigma_{m}}
\end{aligned}
$$

where $\varepsilon_{p}$ is the permittivity of the particle, $\sigma_{p}$ the conductivity of the particle and $\sigma_{m}$ the conductivity of the medium. Reported values for the constants in these equations for particle (DNA) and media (diluted PBS) range widely depending on experimental conditions.

However, we tried to directly measure or estimate all constants necessary for the calculation as follows. Constants for the diluted PBS, $\varepsilon_{m}$ and $\sigma_{m}$, were measured to be $151 \varepsilon_{0}$ and $2 \mathrm{mS} / \mathrm{m}$, respectively, where $\varepsilon_{0}$ is the vacuum permittivity $\left(8.85 \times 10^{-12} \mathrm{~F} / \mathrm{m}\right)$. Compared to these constants for continuous media, $\varepsilon_{p}$ and $\sigma_{p}$ for a DNA molecule are hard to define due to their dependency on the EDL formation on the molecule surface. In early work, researchers studied conductivities of a DNA strand in dry conditions, and obtained the very wide range of $10^{-}$ ${ }^{4} \sim 10^{5} \mathrm{~S} / \mathrm{m}$ [40-42]. More recently, the behavior of a DNA molecule in wet conditions, i.e. with water molecules, was investigated $[43,44]$. For $\mu$ TAS researchers, it is more appropriate to adopt permittivity and conductivity as measured in solution to predict their mobility in response to an AC potential. Accordingly, we used experimentally obtained values of $10^{-2}$ $\mathrm{S} / \mathrm{m}$ and $80 \varepsilon_{0}$ for $\varepsilon_{p}$ and $\sigma_{p}$, respectively [40]. Other parameters used in our calculation are: $U_{r m s}=1.77 \mathrm{~V}\left(5 \mathrm{~V}_{\mathrm{pp}}\right), d=5 \mu \mathrm{m}$, and $r_{e}=0.38 \mu \mathrm{m}$. Here, $r_{e}$ was calculated from the StokesEinstein equation:

$$
\begin{aligned}
& r_{e}=\frac{k T}{6 \pi D \eta} \\
& D=\frac{(\Delta d)^{2}}{4 t}
\end{aligned}
$$

where $k$ is the Boltzmann constant, $T$ the temperature, $D$ the diffusion coefficient and $\Delta d$ the mean square displacement within time duration $t$. The data set for $\Delta d$ and $t$ were obtained 
from $10 \lambda$ DNA molecules over $10 \mathrm{~s}$ observation, and successive frames were analyzed to avoid mistracking the moving DNA molecules.

Using all parameters mentioned above, we estimated $F_{D E P}$; these values plotted as solid lines for $R=2,3,4 \mu \mathrm{m}$ in Fig. 3. The graph shows the DEP forces obtained from experimental and numerical calculation together. For both positive and negative DEP, the force range calculated from parameters is about one order of magnitude larger than that of the experimental results from quadrupole electrodes. Similar values for the measured force have also been reported in other experimental conditions [45]. On the other hand, the crossover frequency calculated to be $880 \mathrm{kHz}$ was consistent with the experimental value. Such discrepancy in the force magnitude is mainly caused by the difference in field strength; which is usually much weaker in the experiments than that used in the calculation. However, it is shown that the DEP force of $10^{-13} \sim 10^{-12} \mathrm{~N}$ and the crossover frequency can be estimated by assuming appropriate parameters.

\section{AC-EOF in a DNA concentrator}

To compare with other electrokinetic phenomena, AC-EOF velocity has been measured and calculated numerically for a large electrode [2]. For our DNA concentrator, we measured ACEOF velocity by tracking DNA molecules by PTV. Velocities versus frequency is plotted in Fig. 4. Since the velocities depend on the distance from the electrode centre, we tracked molecules at three different positions: $r=5,10,15 \mu \mathrm{m}(r=0 \mu \mathrm{m}$ is the electrode centre $)$. Each plot was obtained by averaging velocities of over 10 molecules moving on the electrode surface. The velocities were always maximal at $1 \mathrm{kHz}$ for any given electrode position. At the limits of both low and high frequency, velocities reached zero.

We estimated the time-averaged AC-EOF velocity by applying the following model using a linear double-layer approximation, proposed by Green et al. [23],

$$
\left\langle v_{E O F}\right\rangle=\frac{1}{8} \frac{\varepsilon_{m} V_{0}^{2} \Omega^{2}}{\eta z\left(1+\Omega^{2}\right)^{2}}
$$


where $\Omega$ is the nondimensional frequency:

$$
\Omega=\omega \frac{\varepsilon_{m}}{\sigma_{m}} \frac{\pi}{2} z \kappa
$$

For other variables, $V_{0}$ is the amplitude of the AC potential. The distance from the centre of electrode gap, $z$, is regarded as $z=32.5-r(\mu \mathrm{m})$ in our experimental setup. The reciprocal Debye length, $\kappa$, is hard to define, since it depends on concentrations of ion spieces and degree of their ionization. Following other references for dilute solutions with low conductivity, Debye length of $100 \mathrm{~nm}$ was used in our calculation [46, 47]. The derived velocities corresponding to each position $\left(r_{t h}=5,10,15 \mu \mathrm{m}\right)$ where experimental results were obtained are shown as solid curves in Fig. 4. The computed values were much larger than the experimental results. Therefore, in Fig. 4 computed values were matched to experimental results by dividing by 72 , which was determined by focusing on the maximum computed velocity of $17 \mathrm{~mm} / \mathrm{s}$ for $r=15 \mu \mathrm{m}$. This discrepancy can be mainly explained by the difference of the electric field distribution in the model and experiments. The discussion was also reported and the computed velocity was larger by about two orders of magnitude in references $[2,23]$. Not only in the DNA concentrator but also in conventional AC-EOF measurements, the velocity range is of the order of $10 \mathrm{~mm} / \mathrm{s}$ for calculated results and $100 \mu \mathrm{m} / \mathrm{s}$ for experimental results [23]. In view of this discrepancy, it seems reasonable to estimate the velocity of a few hundred $\mu \mathrm{m} / \mathrm{s}$ for our DNA concentrator.

Compared to the large discrepancy for the magnitude of velocity, the frequency dependencies agreed very well. The maximum AC-EOF velocities were computed in the frequency range of $0.5-1 \mathrm{kHz}$, which agrees with the peak experimental velocities at $1 \mathrm{kHz}$. Therefore, the model proposed by Green et al. [23] appears valid to predict the dependency on applied frequency for AC-EOF. 


\section{EP as bias voltage applied in a DNA concentrator}

AC-EOF is a very powerful way to manipulate submicrometre particles which cannot be handled by other forces directly acting on a particle. However, the phenomenon drives the flow not the particles themselves. Accordingly, the DNA concentrator necessitates a force to hold the moving molecules at a certain area for detection. Researchers have proposed a combination of AC-EOF and EP, so-called biased AC-EOF, in which the bias DC voltage of about $1 \mathrm{~V}$ was superimposed on AC voltage $[1,29]$. Such a technique enhances the accumulation of molecules in a designated area on the electrode after flowing them by ACEOF over the concentrator. In addition to the increase in conentrating power manifesting by an increase in fluorescetn intensity, we have found that the bias voltage affects the duration of molecular residence on the electrode centre.

We monitored the fluorescent intensity for two minutes since the voltage was applied, and the time dependency of fluorescent intensity, $I$, was fitted by:

$$
I=A\left(1-e^{-t / \tau}\right)
$$

for $t=0 \sim 40 \mathrm{~s}$ since the fluorescent intensity saturates at about $t=50 \mathrm{~s}$. After $t=60 \mathrm{~s}$ the fluorescent intensity decreased with time. For comparison, fluorescent intensity $I$ for four conditions with different bias voltages of $0,1,2$ and $2.5 \mathrm{~V}$ was normalized with the amplitude $A$ and plotted in Fig. 5. It shows the time dependency of $I / A$, which reveals the decay of $I$ from the maximum value. When no bias voltage was applied, I decreased about $35 \%$. On the contrary, when a bias voltage of $2.5 \mathrm{~V}$ was superimposed, the decrease was less than $5 \%$. We observed electrolysis when over $3 \mathrm{~V}$ was applied. The results show that the bias voltage resulting in the EP force is effective not only to attract molecules to the electrode centre but also to retain them longer at the same position.

Based on these experimental results, we are able to explain the efficiency of the EP effect. Deriving the EP force provides further insights into the comparison with DEP and AC- 
EOF effects. The calculation can be simply achieved by applying reported characteristic parameters for DNA molecules to eq. (2), which can be also expressed as:

$$
F_{E P}=q_{e f f} N_{D N A} E
$$

where $q_{\text {eff }}$ is the effective charge per base pair, and $N_{D N A}$ is the number of base pairs of the DNA molecule [48]. In contrast to conductivity and permittivity of DNA in buffer solutions, electric charge for DNA molecules have been estimated from mobility measurements in capillary electrophoresis, e.g. $0.12 \mathrm{e}^{-/ / b p}$ for $66 \mathrm{kbp}$ plasmid [30], or $0.20 \sim 0.28 \mathrm{e}^{-/ \mathrm{bp}}$ for $20 \mathrm{bp}$ double strand DNA [31]. These values derived from mobilities depend on the environment of DNA molecule: in gel fiber structure, known as capillary gel electrophoresis, the effective charge of DNA molecule tends to increase because the anchor force acting on the DNA increases. It is caused by the lower mobility of the free counterions on the DNA which decrease the drag force. On the other hand, in gel-free solution the effective charge tends to be smaller than that measured in gel, e.g. Gurrieri and coworkers report $0.08 \mathrm{e}^{-/ \mathrm{bp}}$ in a buffer solution and $0.32 \mathrm{e}^{-} / \mathrm{bp}$ in $1.2 \%$ agarose gel [32].

In our experimental setup, the highest electric field is provided when the bias voltage of $2.5 \mathrm{~V}$ is applied between $10-\mu \mathrm{m}$ gap ITO electrodes. Now we are able to calculate $F_{E P}$ for a single $\lambda$ DNA molecule to be $(0.16 \sim 1.2) \times 10^{-9} \mathrm{~N}$ using $48.5 \mathrm{kbp}$ of $\lambda$ DNA for $n$ and $0.08 \sim 0.63$ $\mathrm{e}^{-/ b p}$ for $q[30-33,49]$. This EP force is four orders of magnitude larger than the DEP force, as measured and calculated in the previous section. Such a comparison of DEP and EP force reveals that the behavior of DNA molecules is mainly dominated by EP rather than DEP in a high electric field, i.e. on the electrode edge and surface. The results imply that the DNA concentrator attracts molecules to the electrode centre by EP as discussed in references $[1,2]$. Therefore, one is able to design a similar DNA concentrator to ours to utilize AC-EOF and EP. Moreover, for a different experimental setup, one can estimate DEP and EP forces and compare them to determine a more dominant force between them near the electrode surface. The dominant force works as a trapping force and AC-EOF defines a flow pattern. Therefore, 
combining these two phenomena allows us to design a high concentration area in a DNA concentrator. We note that the expected concentration procedure might be disturbed by a repulsive force on molecules, because charge distribution on accumulated molecules or electrode surfaces change after the concentration. However, we could not see a large fluorescent intensity drop for a relatively short concentration duration, up to a few minutes.

\section{Three dimensional DNA molecule distributions}

Mobility of DNA molecules in our DNA concentrator has been discussed above; molecules are attracted by the EP force when they approach the electrode centre by the fluid flow induced by AC-EOF. Such concentration processes were investigated two dimensionally, and only AC-EOF on a pair of coplanar electrodes was visualized three dimensionally. The three dimensional distribution of molecules in the DNA concentrator has not been considered yet.

Here, we first monitored three dimensional DNA distributions on the electrode as shown in Fig. 6. Images were captured by scanning confocally from the electrode surface $(\mathrm{z}=0 \mu \mathrm{m})$ into the bulk solution region where no $\mathrm{AC}-\mathrm{EOF}$ was observed $(\mathrm{z}=30 \mu \mathrm{m})$ with 1$\mu \mathrm{m}$ step. Scanning was started after a 2 min concentration process and ended in $30 \mathrm{~s}$, resulting in 30 image frames. Only five images for $\mathrm{z}=0,1,2,4$ and $6 \mu \mathrm{m}$ are shown in Fig. 6; The experiment was performed with no bias and 1-V bias voltage, as shown in (a) and (b), respectively.

The effect of EP force is clearly seen in the two experimental conditions. At $\mathrm{z}=0 \mu \mathrm{m}$, more DNA molecules were attracted to the electrode surface when the bias voltage was applied. Even in the upper location of the electrode, 1-V bias voltage yielded brighter and larger fluorescent area than with no bias voltage applied up to $\mathrm{z}=6 \mu \mathrm{m}$. It is probable that fluorescence from molecules out of the focal plane may increase the fluorescent intensity at each scanned position. Taking such phenomena into consideration, we are still able to conclude the DNA molecules are attracted not only the electrode surface but also above the 
electrode. Three dimensional accumulation of the DNA molecules at the electrode centre is advantageous to obtain higher fluorescent detection intensity by epi-fluorescent illumination in the depth direction. These DNA distributions have a good agreement with flow patterns estimated by several numerical and experimental methods, though some of them have different electrode patterns $[2,24,29,50]$. Especially, our result shows the mobility of each DNA molecule corresponding to the flow pattern and some molecules are stretched along the electric field. It is achieved by our transparent ITO electrodes much smaller than other studies to utilize the inverted microscope with a 100x objective.

\section{Conclusions}

We have investigated three major electrokinetic phenomena, DEP, EP and AC-EOF, in a DNA concentrator focusing on the mobility of $\lambda$ DNA molecules. The DEP force, $F_{D E P}$, for a $\lambda$ DNA molecule is found to have a magnitude of $10^{-13} \mathrm{~N}$ range in both positive and negative DEP from the velocity measurement using quadrupole electrodes. Based on the fundamental DEP force formula, $F_{D E P}$ is estimated to be $10^{-12} \mathrm{~N}$, which is one order of magnitude larger than the experimental result. However, the crossover frequency of $880 \mathrm{~Hz}$ is consistent with the experimental result. AC-EOF velocity measurements show a large discrepancy from the magnitude of results computed by a theoretical model, roughly a factor of $1 / 72$. However, the frequency dependency of the flow velocity agree well; We find a maximum velocity at $1 \mathrm{kHz}$ and decrease at lower and higher frequency range. The resulting maximum velocity in our concentrator was in the order of 100 200 $\mu \mathrm{m} / \mathrm{s}$. A DC bias voltage superimposed on AC voltage helps to retain DNA molecules. This is explained by estimating the EP force, $F_{E P}$, acting on the molecule; The resulting value of $(0.16 \sim 1.2) \times 10^{-9} \mathrm{~N}$ is three to four orders of magnitude larger than $F_{D E P}$. Confocal laser scanning microscopy reveals that the bias voltage attracts more molecules three dimensionally and increase fluorescent intensity at the electrode centre. 
Most studies reported on the DNA concentrator were mainly based on trial-and-error optimization of these phenomena. However, our experimental and theoretical approach to understand the DNA concentrator show that AC-EOF is totally dominant for bulk transport of molecules. Comparing the two forces acting on a DNA molecule, the EP force works much better than the DEP force for trapping molecules on the electrode in our experimental setup. Moreover, several important parameters such as $F_{D E P}, F_{E P}$ and $\left\langle v_{E O F}\right\rangle$ can be simply calculated for the purpose of designing a concentrator. Threfore, a similar concentrator can be designed based on our and reported results. When a designe parameter is modified, we are still able to calculate DEP and EP forces to determine a dominant force. It will allow us to expect a concentration area on a concentrator by the integration of the dominant force along with an electroosmosis flow pattern. This methodology should help to understand how the designed molecular concentrator works in $\mu$ TAS.

\section{Acknowledgements}

This study was partially supported by the Kyoto Nanotechnology Cluster and Cooperation of Innovative Technology and Advanced Research in City Area Program in the Southern Area of Lake Biwa (2007-2009) from the Ministry of Education, Culture, Sports, Science and Technology, Government of Japan (MEXT). This research was also funded by PRESTO, CREST and Research for Promoting Technological Seeds grant (09-043) from Japan Science and Technology Agency (JST). We acknowledge Prof. K. Terao of Department of Intelligent Mechanical Systems Engineering, Kagawa University, Japan, and Prof. H. Kotera of Department of Microengineering, Kyoto Univeristy, Japan, for using the a confocal laser scanning system. Authors also thank Prof. P. K. Wong of Aerospace \& Mechanical Engineering Department, The University of Arizona, USA, for discussion on results and Prof. J. C. Wells of Department of Civil Engineering, Ritsumeikan University, Japan, for critical reading of this paper. 


\section{References}

[1] P. K. Wong, C. Y. Chen, T. H. Wang and C. M. Ho, Electrokinetic bioprocessor for concentrating cells and molecules, Anal Chem, 76 (2004) 6908-14

[2] M. Bown and C. Meinhart, AC electroosmotic flow in a DNA concentrator, Microfluidics and Nanofluidics, 2 (2006) 513-523

[3] P. R. Gascoyne and J. Vykoukal, Particle separation by dielectrophoresis, Electrophoresis, 23 (2002) 1973-83

[4] J. D. Yantzi, J. T. Yeow and S. S. Abdallah, Multiphase electrodes for microbead control applications: integration of DEP and electrokinetics for bio-particle positioning, Biosens Bioelectron, 22 (2007) 2539-45

[5] A. Ramos, H. Morgan, N. G. Green and A. Castellanos, Ac electrokinetics: a review of forces in microelectrode structures, J. Phys. D: Appl. Phys., 31 (1998) 2338-2253

[6] M. P. Hughes, AC electrokinetics: applications for nanotechnology, Nanotechnology, 11 (2000) 124-132

[7] T. B. Jones, Electromechanics of Particles. Cambridge: Cambridge University Press, 1995.

[8] M. Washizu and O. Kurosawa, Electrostatic manipulation of DNA in microfabricated structures, IEEE Trans. Ind. Applicat., 26 (1990) 1165-1172

[9] M. Washizu, O. Kurosawa, I. Arai, S. Suzuki and N. Shimamoto, Applications of electrostatic stretch-andpositioning of DNA, IEEE Trans. Ind. Applicat., 31 (1995) 447-456

[10] J. Kentsch, M. Durr, T. Schnelle, G. Gradl, T. Muller, M. Jager, A. Normann and M. Stelzle, Microdevices for separation, accumulation, and analysis of biological micro- and nanoparticles, IEE Proc Nanobiotechnol, 150 (2003) 82-89

[11] J. V. Peter R. C. Gascoyne, Particle separation by dielectrophoresis, Electrophoresis, 23 (2002) 1973-1983

[12] Jung and H.-Y. Kwak, Separation of Microparticles and Biological Cells Inside an Evaporating Droplet Using Dielectrophoresis, Anal. Chem., 79 (2007) 5087-5092

[13] H. Morgan, M. P. Hughes and N. G. Green, Separation of Submicron Bioparticles by Dielectrophoresis, 77 (1999) $516-525$

[14] X. B. Wang, Y. Huang, X. Wang, F. F. Becker and P. R. Gascoyne, Dielectrophoretic manipulation of cells with spiral electrodes, Biophys J, 72 (1997) 1887-99

[15] M. Suzuki, T. Yasukawa, H. Shiku and T. Matsue, Separation of Live and Dead Microorganisms in a Micro-Fluidic Device by Dielectrophoresis, Bunseki Kagaku, 54 (2005) 1189-1195

[16] P. R. C. Gascoyne, J. Noshari, F. F. Becker and R. Pethig, Use of dielectrophoretic collection spectra for characterizing differences between normal and cancerous cells, Industry Applications, IEEE Transactions on, 30 (1994) 829-834

[17] M. P. Hughes and H. Morgan, Dielectrophoretic characterization and separation of antibody-coated submicrometer latex spheres, Anal. Chem., 71 (1999) 3441-3445

[18] X. Hu, P. H. Bessette, J. Qian, C. D. Meinhart, P. S. Daugherty and H. T. Soh, Marker-specific sorting of rare cells using dielectrophoresis, Proc Natl Acad Sci U S A, 102 (2005) 15757-61

[19] M. Castellarnau, A. Errachid, C. Madrid, A. Juaez and J. Samitier, Dielectrophoresis as a Tool to Characterize and Differentiate Isogenic Mutants of Escherichia coli, Biophysical Journal, 91 (2006) 3937-3945 
[20] S. P. Desai, M. D. Vahey and J. Voldman, Electrically addressable vesicles: tools for dielectrophoresis metrology, Langmuir, 25 (2009) 3867-75

[21] P. K. Wong, T.-H. Wang, J. H. Deval and C.-M. Ho, Electrokinetics in Micro Devices for Biotechnology Applications, IEEE/ASME Trans. Mechatron., 9 (2004) 366-376

[22] M. L. Y. Sin, Y. Shimabukuro and P. K. Wong, Hybrid electrokinetics for separation, mixing, and concentration of colloidal particles, Nanotechnology, 20 (2009) 165701

[23] N. G. Green, A. Ramos, A. Gonzalez, H. Morgan and A. Castellanos, Fluid flow induced by nonuniform ac electric fields in electrolytes on microelectrodes. I. Experimental measurements, Phys Rev E, 61 (2000) 4011-8

[24] N. G. Green, A. Ramos, A. Gonzalez, H. Morgan and A. Castellanos, Fluid flow induced by nonuniform ac electric fields in electrolytes on microelectrodes. III. Observation of streamlines and numerical simulation, Phys Rev E, 66 (2002) 026305

[25] A. Ramos, A. Gonzalez, A. Castellanos, N. G. Green and H. Morgan, Pumping of liquids with ac voltages applied to asymmetric pairs of microelectrodes, Physical Review E, 67 (2003) 056302

[26] A. B. D. Brown, C. G. Smith and A. R. Rennie, Pumping of water with ac electric fields applied to asymmetric pairs of microelectrodes, Physical Review E, 63 (2000) 016305

[27] S. Debesset, C. J. Hayden, C. Dalton, J. C. Eijkel and A. Manz, An AC electroosmotic micropump for circular chromatographic applications, Lab Chip, 4 (2004) 396-400

[28] N. Sasaki, T. Kitamori and H. B. Kim, AC electroosmotic micromixer for chemical processing in a microchannel, Lab Chip, 6 (2006) 550-4

[29] J. Wu, Biased AC electro-osmosis for on-chip bioparticle processing, Nanotechnology, IEEE Transactions on, 5 (2006) 84-89

[30] S. B. Smith and A. J. Bendich, Electrophoretic charge density and persistence length of DNA as measured by fluorescence microscopy, Biopolymers, 29 (1990) 1167-73

[31] T. M. Laue, T. M. Ridgeway, J. O. Wooll, H. K. Shepard, T. P. Moody, T. J. Wilson, J. B. Chaires and D. A. Stevenson, Insights from a new analytical electrophoresis apparatus, J Pharm Sci, 85 (1996) 1331-5

[32] S. Gurrieri, S. B. Smith and C. Bustamante, Trapping of megabase-sized DNA molecules during agarose gel electrophoresis, Proc Natl Acad Sci U S A, 96 (1999) 453-8

[33] U. F. Keyser, B. N. Koeleman, S. van Dorp, D. Krapf, R. M. M. Smeets, S. G. Lemay, N. H. Dekker and C. Dekker, Direct force measurements on DNA in a solid-state nanopore, Nat Phys, 2 (2006) 473-477

[34] H. Watarai, T. Sakamoto and S. Tsukahara, In Situ Measurement of Dielectrophoretic Mobility of Single Polystyrene Microparticles, Langmuir, 13 (1997) 2417-2420

[35] Y. Huang and R. Pethig, Electrode design for negative dielectrophoresis, Measurement Science and Technology, 2 (1991) 1142-1146

[36] S. Tsukahara, T. Sakamoto and H. Watarai, Positive Dielectrophoretic Mobilities of Single Microparticles Enhanced by the Dynamic Diffusion Cloud of Ions, Langmuir, 16 (2000) 3866-3872

[37] Y. Zhao, U.-C. Yi and S. K. Cho, Microparticle Concentration and Separation by Traveling-Wave Dielectrophoresis (twDEP) for Digital Microfluidics, Microelectromechanical Systems, Journal of, 16 (2007) 14721481 
[38] M. P. Hughes, H. Morgan, F. J. Rixon, J. P. H. Burt and R. Pethig, Manipulation of herpes simplex virus type 1 by dielectrophoresis, Biochimica et Biophysica Acta (BBA) - General Subjects, 1425 (1998) 119-126

[39] S. Tsukahara and H. Watarai, Dielectrophoresis of microbioparticles in water with planar and capillary quadrupole electrodes, IEE Proc. - Nanobiotechnol., 150 (2003) 59-65

[40] M. Hoeb, J. O. Radler, S. Klein, M. Stutzmann and M. S. Brandt, Light-induced dielectrophoretic manipulation of DNA, Biophys J, 93 (2007) 1032-8

[41] H. W. Fink and C. Schonenberger, Electrical conduction through DNA molecules, Nature, 398 (1999) 407-10

[42] Y. Zhang, R. H. Austin, J. Kraeft, E. C. Cox and N. P. Ong, Insulating behavior of lambda-DNA on the micron scale, Phys Rev Lett, 89 (2002) 198102

[43] P. Tran, B. Alavi and G. Gruner, Charge transport along the lambda-DNA double helix, Phys Rev Lett, 85 (2000) $1564-7$

[44] T. Kleine-Ostmann, C. Jordens, K. Baaske, T. Weimann, M. H. de Angelis and M. Koch, Conductivity of singlestranded and double-stranded deoxyribose nucleic acid under ambient conditions: The dominance of water, Applied Physics Letters, 88 (2006) 102102-3

[45] C. F. Chou, J. O. Tegenfeldt, O. Bakajin, S. S. Chan, E. C. Cox, N. Darnton, T. Duke and R. H. Austin, Electrodeless dielectrophoresis of single- and double-stranded DNA, Biophys J, 83 (2002) 2170-9

[46] S. Kumagai, S. Yoshii, K. Yamada, I. Fujiwara, N. Matsukawa and I. Yamashita, Nanopatterning of Vapordeposited Aminosilane Film using EB Lithography for Ferritin Protein Adsorption, J Photopolym Sci Technol, 18 (2005) 495-500

[47] Z. Stojek, Electroanalytical Methods: Guide to Experiments and Applications, in: F. Scholz and A. M. Bond (Eds.), Electroanalytical Methods: Guide to Experiments and Applications, Springer, Berlin, 2005, pp. 3-8.

[48] H. J. Jung and Y. C. Bae, Theory for the capillary electrophoretic separation of DNA in polymer solutions, Journal of Chromatography A, 967 (2002) 279-287

[49] I. Koltover, K. Wagner and C. R. Safinya, DNA condensation in two dimensions, Proc Natl Acad Sci U S A, 97 (2000) 14046-51

[50] K. F. Hoettges, M. B. McDonnell and M. P. Hughes, Use of combined dielectrophoretic/electrohydrodynamic forces for biosensor enhancement, Journal of Physics D: Applied Physics, 36 (2003) L101-L104 


\section{Figure captions}

Fig. 1 (a) Quadrupole ITO electrodes for DEP measurements. (b) Circular ITO electrodes for the DNA concentrator. The centre electrode was always positive when the DC bias voltage was applied.

Fig. 2 Measured DEP velocity for $\lambda$ DNA molecules depending on the radial distance from the electrode centre, $R$.

Fig. 3 Comparison of the DEP forces, $F_{D E P}$. Symbols referring to the left $y$-axis show $F_{D E P}$ obtained by the quadrupole experiments. Solid lines referring to the right $y$-axis indicate $F_{D E P}$ calculated numerically.

Fig. 4 AC-EOF velocity on the DNA concentrator. Symbols with error bars connected by dotted line show the measured velocity depending on the position on the centre electrode. Solid lines are $\left\langle v_{E O F}\right\rangle$ derived numerically and multiplied by a correction factor of 1/72.

Fig. 5 Normalized fluorescent intensity (FI) at the electrode centre. It was monitored with different bias voltages $0,1,2$ and $2.5 \mathrm{~V}$, and reached the maximum in $40 \mathrm{~s}$ in any condition. However, after $120 \mathrm{~s}$ the intensity decayed $35 \%$ when no voltage applied, but just $5 \%$ with a bias voltage of $2.5 \mathrm{~V}$.

Fig. 6 DNA distribution in the depth direction on the electrode centre. (a) When no bias voltage was applied, molecules are attracted near the electrode surface only: two dimensional concentration. (b) More molecules are attracted three dimensionally with a bias voltage of $1 \mathrm{~V}$. Centre electrodes are indicated by white circles corresponding to the schematic illustration shown in Fig. 1b. 


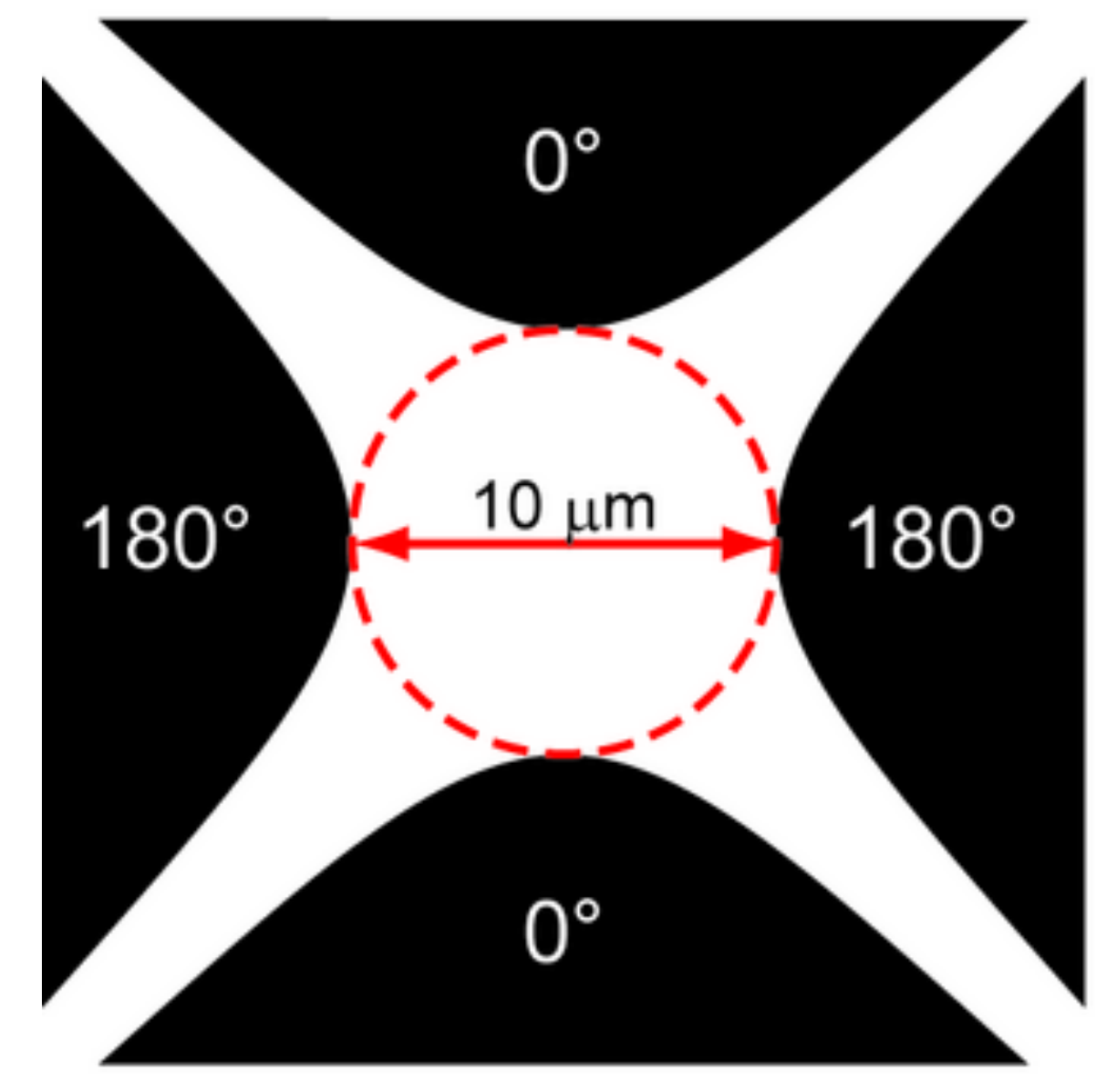

(a)

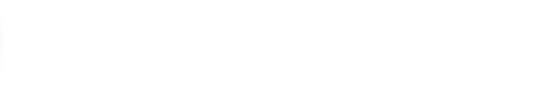

(b)

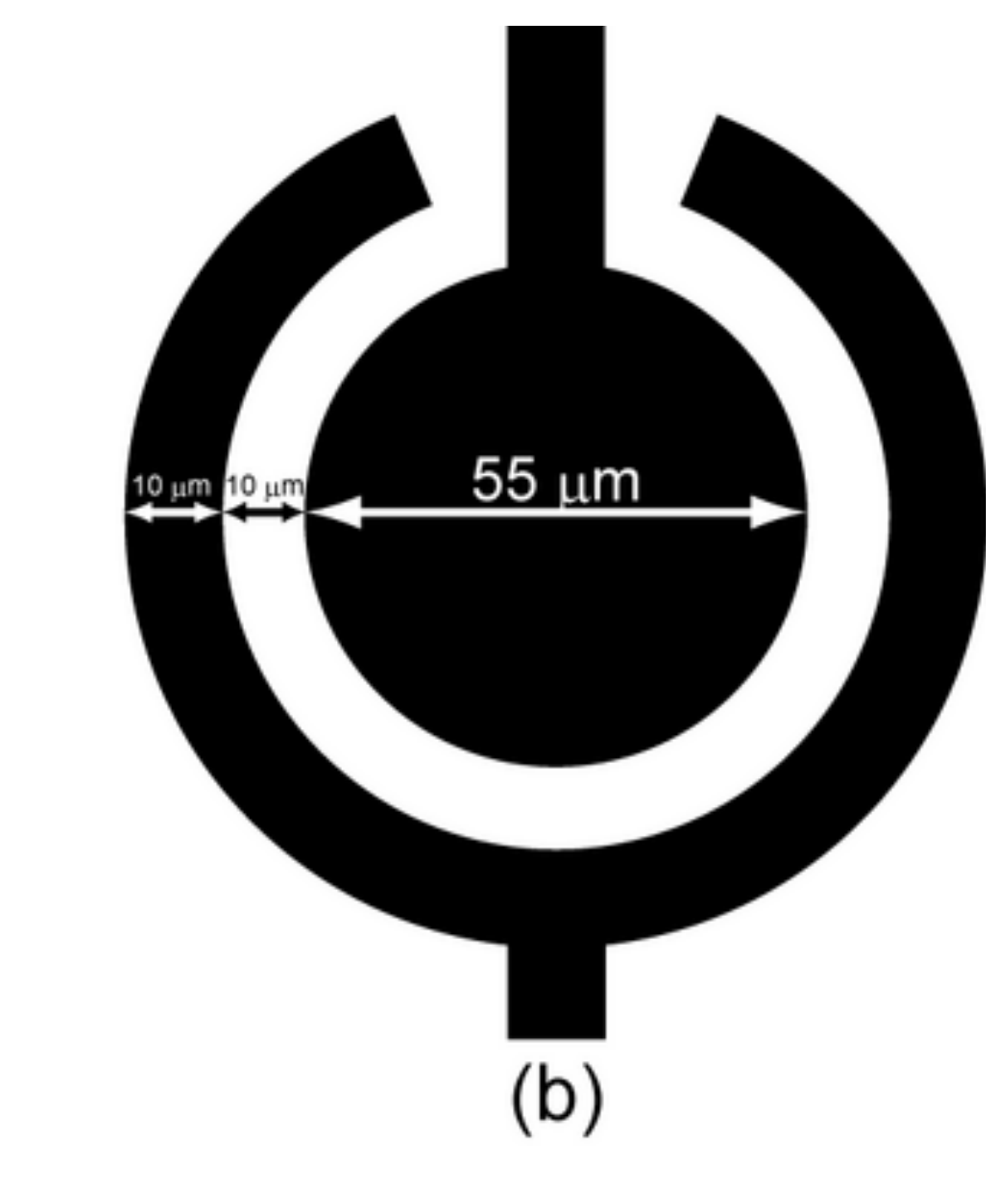

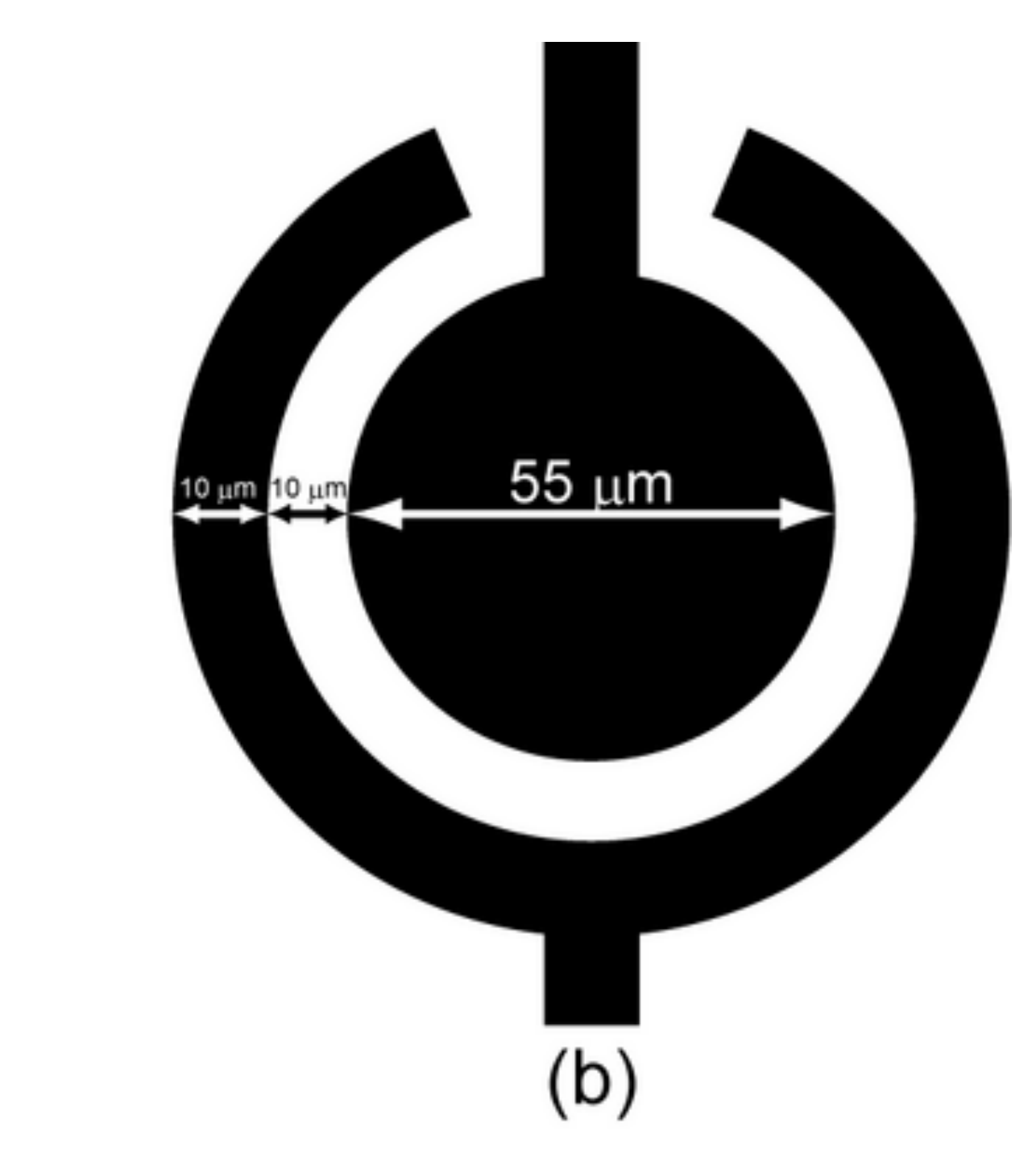

click here to download high re
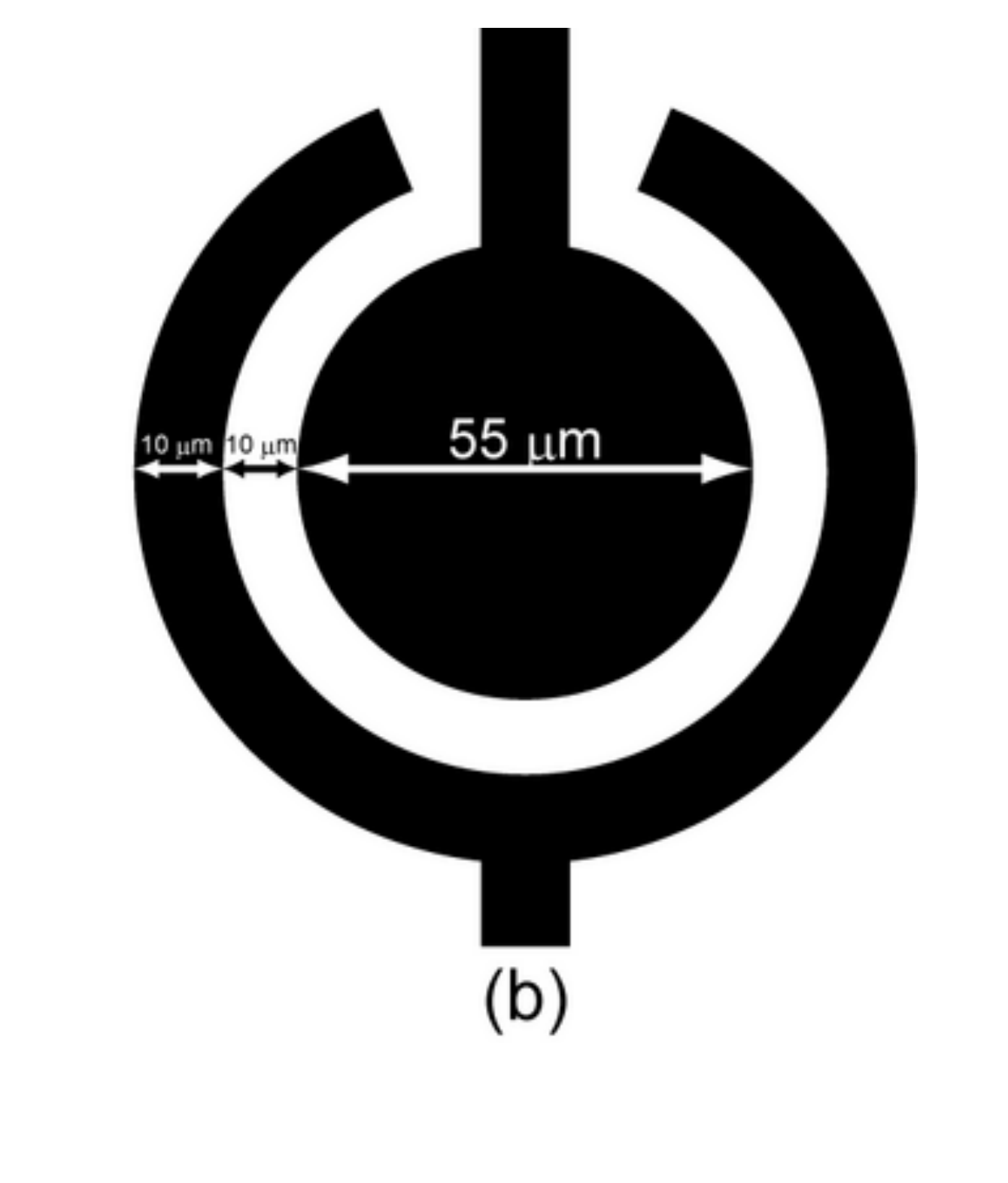

$$
\text { - }
$$




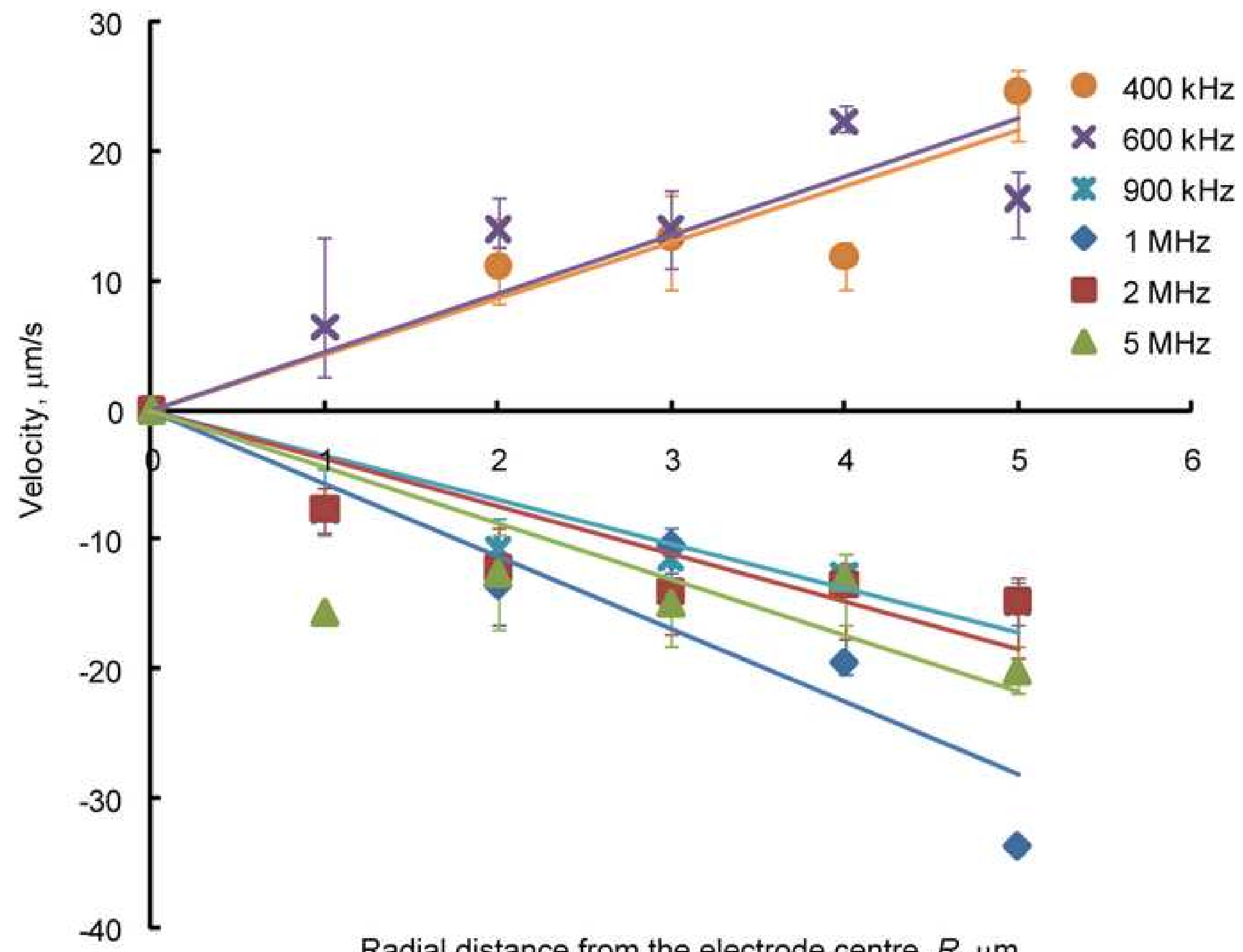

Radial distance from the electrode centre, $R, \mu \mathrm{m}$ 


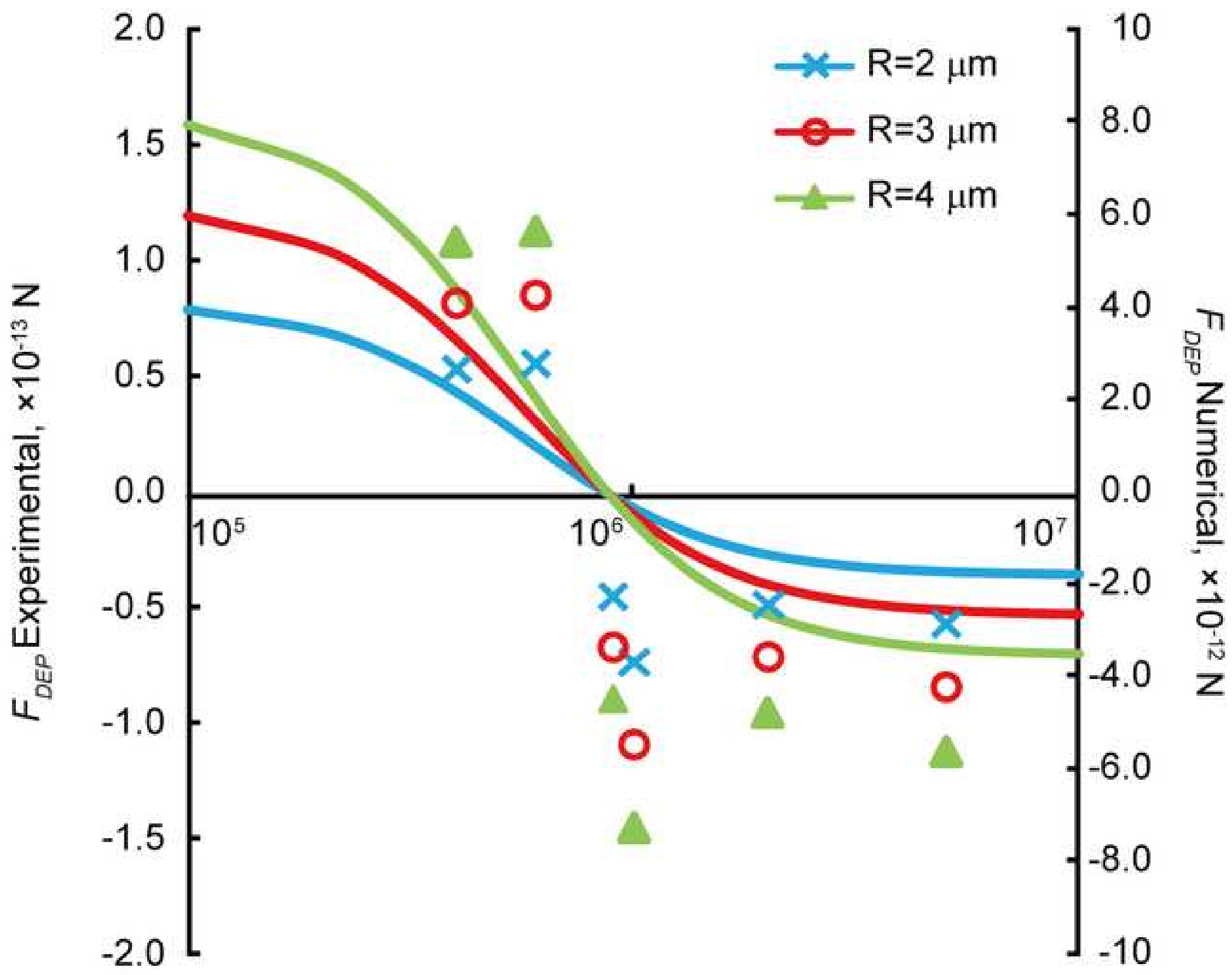

Frequency, $\mathrm{Hz}$ 


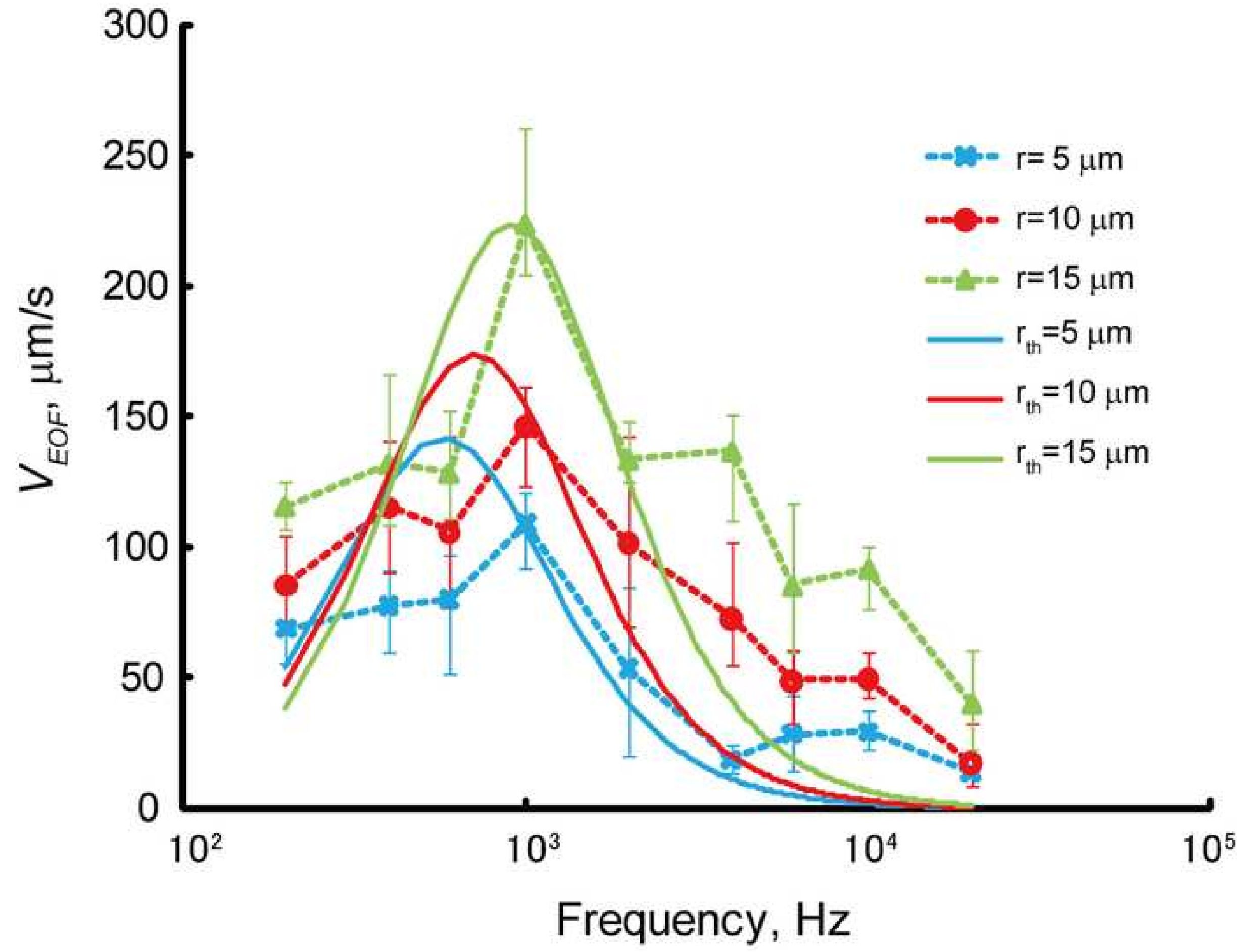




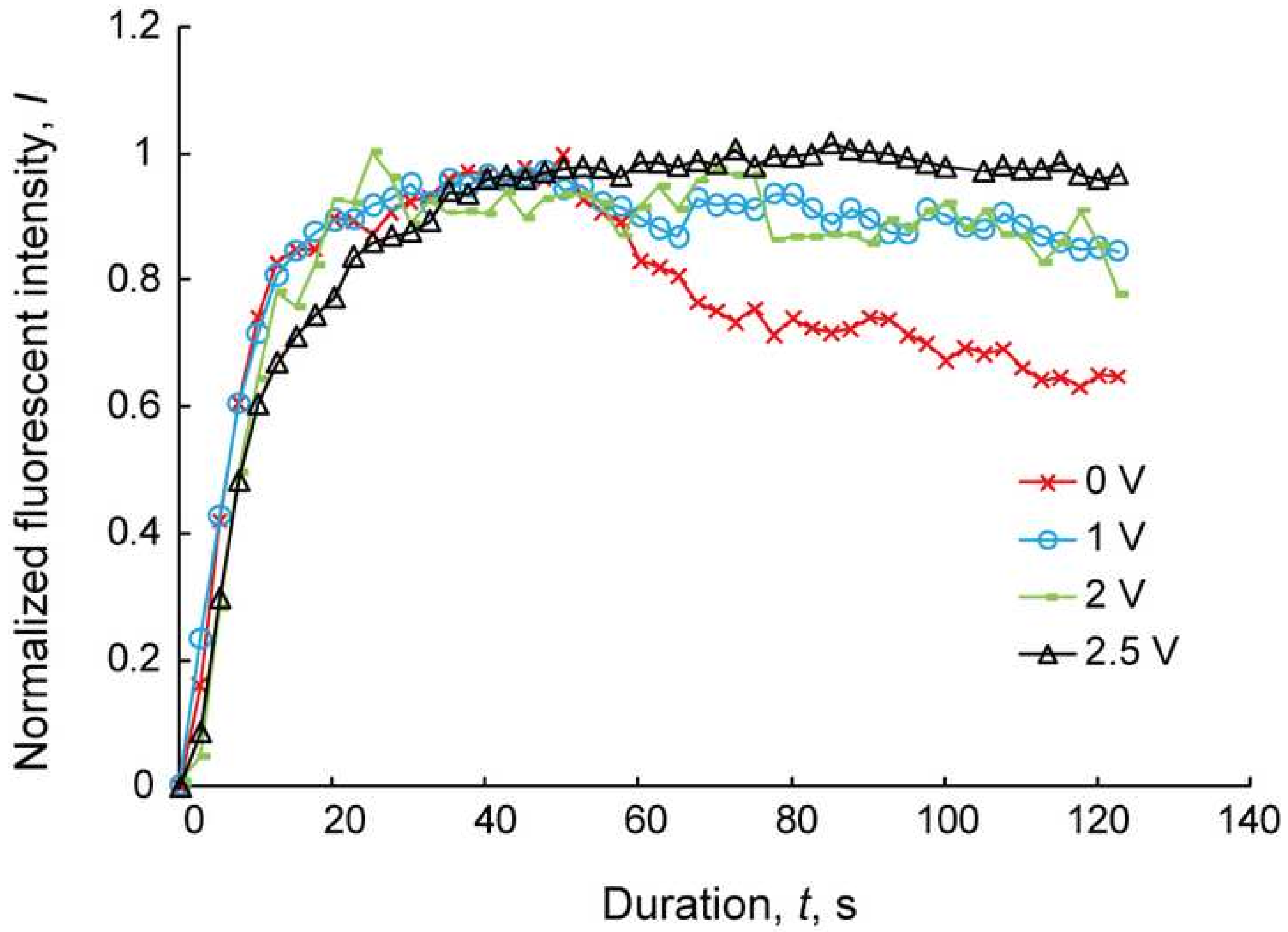



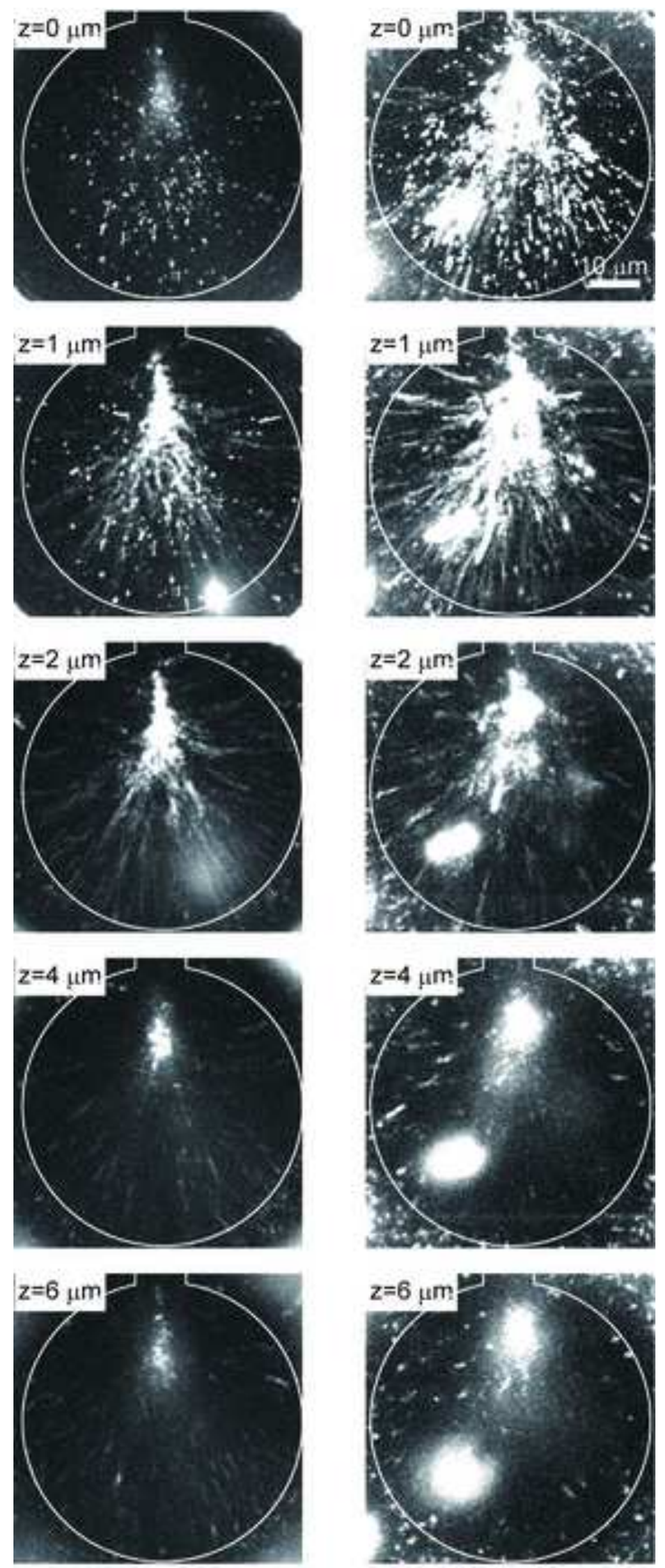

(a) Bias $0 \mathrm{~V}$

(b) Bias $1 \mathrm{~V}$ 